\title{
A TÉCNICA DAS PIRÂMIDES DE VEGETAÇÃO APLICADA A ANÁLISE DE UNIDADES FLORESTAIS DE VEGETAÇÃO ARBÓREA DENSA NO PANTANAL DO ABOBRAL
}

\author{
Mariane Zambone Sakuma ${ }^{(a)}$, Mauro Henrique Soares da Silva ${ }^{(b)}$ \\ (a) Curso de Ciências Biológicas, Universidade Federal do Mato Grosso do Sul, marianesakuma@ gmail.com \\ (b) Curso de Geografia, Universidade Federal do Mato Grosso do Sul, mauro.soares@ufms.br
}

\section{EIXO: BIOGEOGRAFIA, MANEJO DE ÁREAS NATURAIS E PROTEGIDAS: CONSERVAÇÃO DA BIODIVERSIDADE}

\begin{abstract}
Resumo:
$\mathrm{O}$ trabalho se refere à paisagem do Pantanal do Abrobral, uma das sub-regiões do Pantal Sul-matogrossense, dos quais possuem unidades florestais de vegetação densa denominada pela comunidade local de Cordilheiras ou Capões, sendo esses objetivos do presente estudo. Tais unidades de paisagem são, em geral, circundadas por planície cobertas por campo nativos do Cerrado. No entanto estas Cordilheiras e Capões do Pantanal são unidades cobertas por vegetação densa, possui uma leve elevação que permite que estas áreas não sofram com o alagamento ocorrido em determinado período todos os anos, sendo utilizada assim para abrigar a fauna do local. Estas unidades de vegetação esta passando por um processo de degradação devido a presença forte da pecuária e é atravéz de analises de especies encontradas que podemos definir o grau de degradação. Deste modo o estudo procura compreender a estrutura e dinâmica desses sistemas florais. O estudo foi realizado por meio de fichas biogeográficas em parcelas de $400 \mathrm{~m}^{2}$, cujos resultados foram expressos graficamente em Pirâmides de Vegetação.
\end{abstract}

Palavras chave: Pirâmide de Vegetação; Pantanal; Pantanl Sul-matogrossense; Paisagem; Pantanal do Abobral

\section{Introdução}

O Pantanal do Abobral, reconhecido pela sua complexa zona úmida, seu potencial agropecuário e sazonalidade climática o que dinamizou a formação de distintas unidades da paisagem. Dentre elas as cordilheiras, que possuem uma forma estreita, alongam e em seu centro um relevo positivo, levemente elevado e capões, que possuem uma forma mais arredondada que as cordilheiras, ambas compostas por cobertura arbórea densa, se revelando de suma importância ecológica, uma vez que estes ambientes se distinguem das paisagens de áreas mais aplainadas, mesmo sendo ambientes próximos e interligados, principalmente por possuírem uma ligeira elevação, construindo assim uma paisagem com vegetação arbóreas densas usada como refugio da fauna em época de cheia, além de permanecer intacta na seca resistindo as queimadas comum na região. 
Assim, considera-se de grande importância compreensão da estrutura e dinâmica da cobertura vegetal dessas unidades, principalmente ao se considerar as pressões ambientais provindas do uso do solo pautado na pecuária extensiva tão forte e crescente na região.

O objetivo geral desta pesquisa é compreender as organizações estruturais da cobertura vegetal de uma unidade florestal de vegetação arbórea densa (Cordilheira) na paisagem do Pantanal do Abobral.

\section{Material e Método}

Inicialmente foi selecionada uma unidade florestal (Cordilheira) dentro do Pantanal do Abobral. Posteriormente foi estabelecida uma parcela com área 20 x $20 \mathrm{~cm}$, ou seja, $400 \mathrm{~m}^{2}$, onde foram realizados os seguintes procedimentos: a Coleta de amostras de planta, utilizando a técnica de herborização, que consiste em coletar plantas, frutos, flores e raízes, prensá-las e secá-las para posterior identificação em laboratório; a Contagem dos indivíduos por estratos: arbóreo, arbustivo e herbáceo; a análise dos parâmetros abundância e dominância, isto é, a superfície coberta pelas plantas; o grau de sociabilidade, ou seja, agrupamento das plantas ( Tabela I ).

\begin{tabular}{|l|l|l|l|}
\hline \multicolumn{2}{|c|}{ Abundância Dominância } & \multicolumn{2}{|c|}{ Sociabilidade } \\
\hline 5 & Cobrindo entre 75\% e $100 \%$. & 5 & População contínua; manchas densas. \\
\hline 4 & Cobrindo entre 50\% e 75\%. & 4 & $\begin{array}{l}\text { Crescimento em pequenas colônias; manchas } \\
\text { densas pouco extensas. }\end{array}$ \\
\hline 3 & Cobrindo entre 25\% e 50\%. & 3 & Crescimento em grupos. \\
\hline 2 & Cobrindo entre 10\% e 25\%. & 2 & Agrupados em 2 ou 3. \\
\hline 1 & $\begin{array}{l}\text { Planta abundante, porém com valor de } \\
\text { cobertura baixo, nãouperando a 10\%. }\end{array}$ & 1 & 1 indivíduos isolados. \\
\hline+ & Alguns raros exemplares & + & Planta rara ou isolada. \\
\hline
\end{tabular}

Tabela I - Critérios para a classificação da Abundaância-Dominância e da Sociabilidade (Passos, 2003)

Uma vez realizado o parcelamento de um setor da unidade, o qual foi considerado como representante o estado médio da formação vegetal, em seguida, efetuou-se as anotações na ficha biogeográfica, relacionando as espécies vegetaçãos mais importante que ocorrem na formação, segundo os estratos, e detalham-se os fatores biogeográficos que influem na referida formação vegetal, além de analisar a dinâmica, do conjunto observado.

Posteriormente ao levantamento fitossociológico, as espécies coletadas foram transportadas para o Laboratório de Botânica e o Herbário da UFMS/CPTL, para identificação de todas as espécies amostradas. Os dados registrados nas fichas fitossociológicas foram posteriormente compiladas graficamente por meio 
do uso softwares Corel Draw x7 para a elaboração das pirâmides de Vegetação. Essas adaptação da metodologia é adaptada de Passos (2003)

Silva (2016) afirma que o método das Pirâmides de Vegetação como ferramenta para a análise ambiental permite além de compreender a estrutura vertical da vegetação, analisar as relações biogeográficas da composição florística e dinâmica fitossociológica nos estratos e entre eles. Deste modo, é necessário um detalhado levantamento da organização espacial das espécies por meio do inventário nas fichas biogeográficas, seguido da tabulação e organização gráfica dos dados, explorando a precisão na semiologia, de modo a melhor representar a cobertura vegetal como componente do complexo paisagístico.

\section{Resultados e Discussões}

Os resultados apontaram que a unidade estudada é composta por 19 espécies, sendo portanto a área composta por 243 indivíduos jovens e adultos quantificados. Tais indivíduos corroboram para uma estrutura da cobertura vegetal constituída e herbáceos. A dinâmica desta cobertura vegetal revelou um porte arbóreo constituído de população contínua com manchas densas, cobrindo entre $75 \%$ a $100 \%$ da

parcela, ja o porte arbustivo possuía plantas abundantes porém a cobertura da parcela não ultrapassava $10 \%$, uma vez que os indivíduos desse porte se agrupavam de modo isolado. Enfim, o porte herbáceo apresentou alguns raros exemplares de indivíduos isolados. (Figura 01)

Dentre as dezenove espécies encontradas, no porte Abóreo, 220 indivíduos sendo 149 jovens. A espécie de maior ocorrência com 167 indivíduos, 128 jovens, foi Scheelea phalerata ou popularmente Acuri que possui grande importância como fonte de alimento para fauna local e o gado. Sua sociabilidade compreende uma população contínua, manchas densas. Destacou-se também a espécie Rhamnidium elaecarpum, com 15 indivíduos no qual apenas 6 atingiam o porte comum ao individuo adulto. Esta especie possui uma ecologia característica de área desmatada, e sua dinâmica no local sugere progressão, brotando facilmente após corte. (Pott A. 1994) 
XVII Simpósio Brasileiro de Geografia Fisica Aplicada

I Congresso Nacional de Geografia Fisica
OS DESAFIOS DA GEOGRAFIA FÍSICA NA FRONTEIRA DO CONHECIMENTO

Instituto de Geociências - Unicamp

Campinas - SP

28 de Junho à 02 de Julho de 2017

\section{LATITUDE: S19²6'08.09" \\ LONGITUDE: W57'03'47.5" \\ TEMP. MÉDIA ANUAL: \\ ÁREA: $103 \mathrm{M}$}

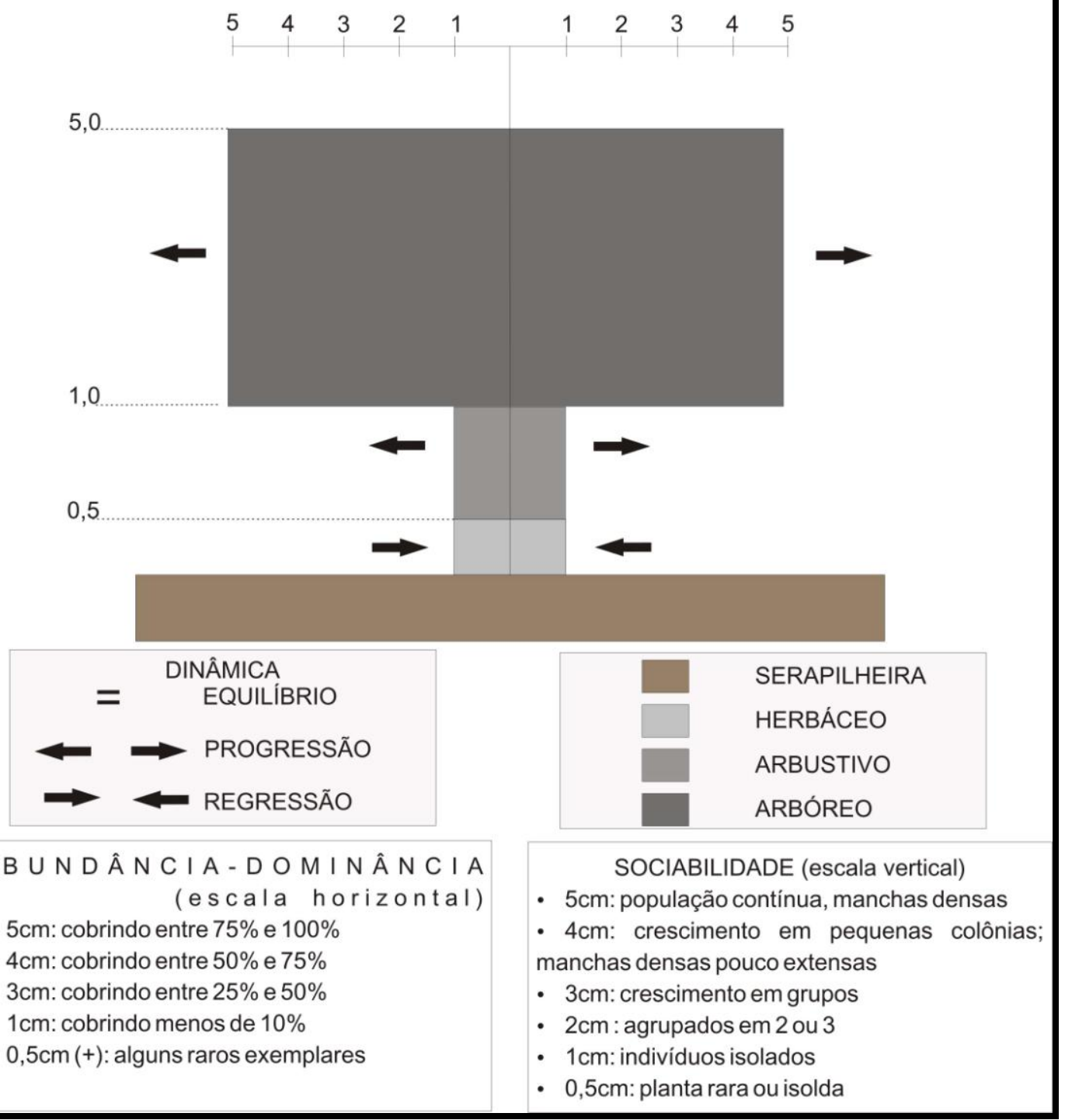

Figura 1 - Pirâmide de Vegetação

Juntamente com as espécies anteriores havia demais espécies de idade adulta cuja a abundânciadominância , cobrindo entre $75 \%$ e 100\%.No porte arbustivo foram encontradas cinco espécies, todos indivíduos jovens. Tendo como destaque a Smilax fluminensis que são bastante características de regiões com tendência a queimadas continuas (Pott A. 1994), sendo encontrado apenas um exemplar, em idade jovem, que pode indicar a ocorrência de queimadas recente .Assim como a espécie Cnidosculus 
aculeatissimus, que também possui resistência a ecologia de região com queimada frequente e temporadas secas (Pott A.1994). Outra espécie que demonstra direta ação do meio é a Phyllanthus que aumenta em ambientes com grande movimentação de animais ou seres humanos e tem preferencia de locais com sombras para crescer (Pott A. 1994). Estas espécies e as demais foram encontradas em idade jovem podendo indicar uma progressão do porte e a influencia do local; Já o porte Herbáceo apenas duas espécies, que possuem uma sociabilidade com raros exemplares e sua abundancia-dominancia constituída por indivíduos isolados. Esta dificuldade de encontrar mais espécies pode indicar um regressão do porte já que uma das espécies encontradas Dioscorea alata possui uma ecologia de fácil adaptação e a outra espécie do gênero Maranta tem boa relação com ambiente que sofre com queimadas e mesmo assim ambas as espécies não são facilmente encontradas. Pode-se também levar em conta que as plantas deste porte, geralmente são baixas e servem de alimento para vários animais, principalmente o gado; Sendo assim não conseguem atingir uma idade pra reprodução podendo justificar a regressão do porte.

\section{Conclusão}

Conclui-se, baseado na estrutura da cobertura vegetal e dinâmica da mesma, que de certo modo, a área estudada pode estar passando por pressões ambientais, podendo ser eles antrópico ou relacionado ao frequente alagamento seguido de secas extremas. Nota-se através da pirâmide que a área ali representada esta em condições instável, materializada pela progressão dos portes arbóreos e arbustivos, no entanto essa progressão não indica boa qualidade ambiental, uma vez que as espécies em destaque são ecologicamente adaptada à região índices de antropização e/ou equilíbrio. Outro fator importante é a regressão identificada para o porte herbáceo, a qual pode estar diretamente ligada a presença de animais exóticos no ambiente representados pelos equinos e bovinos instalados em fazendas da região.

\section{Bibliografia}

PASSOS, M.M. Biogeografia e Paisagem. 2a ed. Maringá - PR, 2003.

POTT, Arnildo Plantas do Pantanal. Empresa Brasileira de Pesquisa Agropecuária, EMBRAPA, Brasília-DF, 1994.

SILVA, M.H.S. Pirâmides de vegetação como estratégia metodológica para análise biogeográfica. IN: DIAS, L.S, e GUIMARÃES, R. B. BIOGEOGRAFIA: Conceitos, metodologia e práticas. Editora ANAP, Tupã-SP, 2016. 